\title{
Analogous simulation of nutrient transformation processes in stream sediments
}

\author{
Yovana Todorova ${ }^{1 *}$, Rumen Belev ${ }^{1}$, Yana Topalova ${ }^{1}$ and Irina Ribarova ${ }^{2}$ \\ 1 Sofia University, Department of General and Applied Hydrobiology, Faculty of Biology, 8 Dragan Tzankov Blvd, 1164 Sofia, Bulgaria \\ ${ }^{2}$ University of Architecture, Civil Engineering and Geodesy, 1 Christo Smirnensky Blvd, 1421 Sofia, Bulgaria
}

\begin{abstract}
The main transformation processes effected by the natural microbial consortium of upper Iskar River with predominant participation of sediment biofilm were simulated in the laboratory by the use of portable devices (chambers). The dynamics of real heterotrophic respiration, organic matter oxidation, denitrification and ammonification were analysed by oxygen depletion, reduction of chemical oxygen demand, nitrate uptake and ammonium accumulation, under the conditions prevailing during high and low flow periods. The experimental results showed fast oxygen consumption and high process rates - indicators for intensive respiration by a heterotrophic microbial consortium and good functioning of the ecosystem component studied. The nitrogen transformations occurred at slower rates but in mutual dynamic balance and their simultaneous realisation was due to precise, adaptive division in time and space.
\end{abstract}

Keywords: respiration, COD-oxidation and nitrogen transformation (RONT) processes, analogous simulation, chambers, river sediments

\section{Introduction}

Streams and rivers are important ecological components and drinking water sources but they are also the main recipients of treated or raw (crude) wastewaters. This is a 2-way street of coincidence in the ecological and technological aspects of water use. To respond effectively to these heterogeneous needs requires specifying what transformation processes happen in river systems with hazardous substances; which of the variations in water parameters are natural modifications and which are results of anthropogenic influence? One area of interest is the study of the biological activity of aquatic organisms responsible for effecting the main nutrient transformations and for the development of the self-purification capacity of the aquatic system. The understanding of these ecological processes provides insight into the functional and structural characteristics of river systems and brings a unifying framework to this area of investigation (Allan, 1995).

The inputs and conversion of energy and materials are important in all river systems and their components. The exchange of water and substances occurs between the surface water, hyporheic strata and sediments. The more intensive processes of nutrient transformation are realised in the boundary zone between these 3 river components. The benthic microbiota associated with sediment biofilms and free organic matter particles at a depth of $10-30 \mathrm{~cm}$ is metabolically the most active and is the main transformation factor in rivers (Pusch and Schwoerbel, 1994). However, the measurement of metabolic activity in this complex system presents practical problems, associated with the multidirectional influence of the environment. A suitable approach to avoid these problems is simulation of natural transformation processes in the laboratory

\footnotetext{
* To whom all correspondence should be addressed.

욜 +35928167289; fax: +35928167289; e-mail: yovanatodorova@yahoo.com

Received 27 November 2007; accepted in revised form 28 July 2009.
}

by the use of portable devices (chambers). These mini-bioreactors are analogous models of a river system and the results obtained can be used for modelling functional aspects of water quality (Dodds and Brock, 1998; Naegeli and Uehlinger, 1997; Uehlinger et al., 2002).

The work presented is part of two scientific research projects, which aim to evaluate and improve water quality models for application to temporary waters in Southern European catchments. Determination of one of the model components - organism fractions - was based on biofilm activity measurement by laboratory simulation of respiration, chemical oxygen demand (COD) oxidation and nitrogen transformation processes (RONT processes).

\section{Materials and methods}

\section{Study site}

The experiment was carried out in the upper subcatchment of the Iskar River, south-western Bulgaria. Geographically Bulgaria is located in the southern part of the temperate zone, in close proximity to the subtropical Mediterranean climatic zone, which determines the moderate continental climate. During the 2nd half of summer and the beginning of autumn, the climate is very often affected by Azores anticyclones, which cause long-lasting dry periods. The Iskar River is the longest river in Bulgaria $(368 \mathrm{~km})$ with an average stream flow of $8.9 \mathrm{~m}^{3} / \mathrm{s}$ recorded for 2004 . The Iskar River and its reservoir are the most economically and socially important water sources in Bulgaria because of their role as a drinking water supply for Sofia (the national capital).

The part of the river that was used as a study site has a clearly-determined seasonal character, with summer and winter low flow (1 to $\left.3 \mathrm{~m}^{3} / \mathrm{s}\right)$, an increase in flow during autumn (6 to $\left.10 \mathrm{~m}^{3} / \mathrm{s}\right)$ and a very distinct spring high water level (15 to $\left.25 \mathrm{~m}^{3} / \mathrm{s}\right)$. The sampling site ( $828 \mathrm{~m} \mathrm{a.} \mathrm{m.} \mathrm{s.} \mathrm{1.)} \mathrm{is} \mathrm{located} 1 \mathrm{~km}$ upstream of the Iskar Dam. Land use in this region consists 


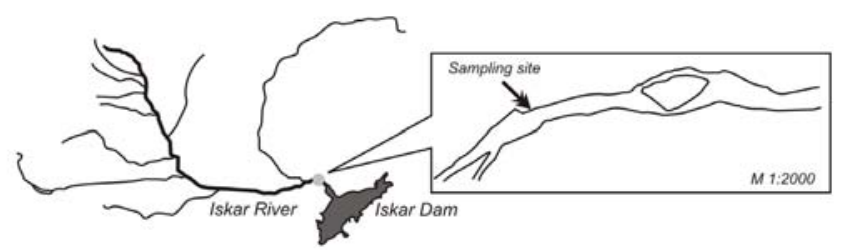

Figure 1

Location of sampling site and investigation scales in the upper subcatchment of the Iskar River

of agriculture, urban areas, woodlands, meadows, pastures and barren/fallow land. The geological substratum is made of gneiss, granite and gravel-sandy deposits. The main pollutants are surplus amounts of nitrogen and phosphorus (farming nonpoint sources), and localised increases of organic and microbial contents from wastewater inputs. For further information on this study site see Kukurin (2005) and Kukurin et al. (2004).

\section{Experimental strategy}

A river section, $500 \mathrm{~m}$ in length (Fig. 1), was treated as a small-scale model of the upper reaches of the Iskar River, and as a bioreactor with a network of sampling points. Preliminary investigations (Topalova et al., 2006) did not detect longitudinal- or cross-gradients in concentrations of nutrients and microbiota at this scale and therefore in this study the river section was considered as a bioreactor with complete mixing. The reduction of the scale of investigation determined 1 sampling point located on the interface between river and bank.

The results reported here were focused on the microbial metabolism in stream-bed sediments. The sampling design included analyses of dynamics of respiration, COD-oxidation and nitrogen transformation (RONT) processes during the high- (May) and low-flow (July) period of 2004. The main transformation processes effected by the natural microbial consortium with predominant participation of sediment biofilm were simulated in the laboratory by use of portable devices (chambers).

The sampling procedure included initial removal of the top sediments in order to eliminate the autotrophic biofilm. The underlying sediment layers ( 5 to $25 \mathrm{~cm}$ depth) were then collected with a spade and deposited into a bucket. In order to standardise substratum structure, natural sediments were sieved (pore size $10 \mathrm{~mm}$ ) and placed in the lower half of each chamber. The rest of the chamber volume was filled with water pumped from the hyporheic zone by a Bou-Rouch pump (Bou, 1974). The chamber (Fig. 2) consisted of a clear Plexiglas tube (inner diameter $52 \mathrm{~mm}$; length $300 \mathrm{~mm}$ ). The bottom of the chamber was a rubber stopper. The chamber was sealed using a stopper with a silicon hose that could be sealed with a hose clamp (Uehlinger et al., 2002). An in situ verification of the $1^{\text {st }}$ stages of the process was carried out by the digging of control chambers in river sediments.

The 2 experiments performed in May and July were designed to simulate respiration and nitrogen transformation processes under different conditions of high and low flow. In May, the simulation was realised at a high initial level of substrata and low temperature. The $1^{\text {st }}$ phase of the process ( 0 to $24 \mathrm{~h}$ ) was studied at $6 \mathrm{~h}$ intervals for determination of intensive aerobic metabolic dynamics in surface sediment layers. In July, the substrata concentrations were limited and analyses were carried out at $24 \mathrm{~h}$ intervals at high temperature. Simultaneously, half the chambers incubated in summer

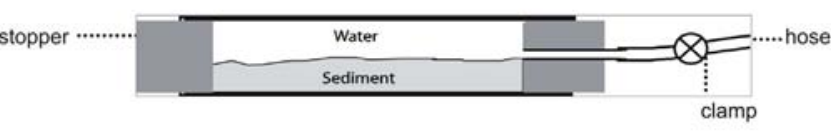

Figure 2

Schematic diagram of the chamber and distribution of sediments during the incubation (TempQsim)

were sparged with gaseous nitrogen for additional reduction of oxygen, by up to $25 \%$. This experimental strategy had 2 main purposes:

- To analyse and compare nutrient transformation processes under different environmental conditions: temperature, initial oxygen, nitrogen and organic concentrations

- To estimate the dynamics of the same processes in simulation of anoxic conditions in deeper sediment layers ( 25 to $35 \mathrm{~cm})$

\section{Analytical procedures}

The physicochemical parameters (temperature, oxygen concentration, and $\mathrm{pH}$ ) of the hyporheic water used for filling the chambers were analyzed in situ with a portable oxygen meter (Handylab Ox1/set) and a pH-meter (Handylab pH11/set; both SCHOTT Instruments, Germany) before sealing the chambers. The samples for laboratory measurements of nitrogen concentration were collected, stored at $4^{\circ} \mathrm{C}$ and transported. These results were treated as the initial $0 \mathrm{~h}$ of simulation. The chambers were transferred to the laboratory and installed in a horizontal position for incubation. The external incubation system was filled with water and stored in the dark to support a constant temperature and to maintain the same light conditions as in the field. At fixed incubation intervals the chambers (in duplicate) were gently inverted and opened. The water phase was analysed in triplicate for determination of COD (dichromatic EPA 410.4/ISO 6060 method, Standard Methods, 1989). Before measurement of ammonium and nitrate concentration the samples were filtered (Cellulose Nitrate Filters, mean pore size $0.45 \mu \mathrm{m})$. The concentrations of nitrogen forms were determined by colorimetric methods according to the BNS-EN-ISO standards (BNS-EN-ISO, 1989).

The rates of aerobic respiration, denitrification and ammonification by the microbial consortium were calculated by measuring oxygen consumption, nitrate decrease and ammonium increase at $24 \mathrm{~h}$ intervals. The results were standardised to a sediment/hyporheic water volume of $1 \mathrm{dm}^{3}(1 \ell)$.

\section{Statistical analysis}

All data are presented as the mean $\pm \mathrm{SD}$ of 3 replicates. Kruskal-Wallis One Way Analysis of Variance on Ranks was used to analyse the differences between the experimental variants. Analyses were performed with SigmaStat 3.10, Systat Software, Inc. Dunn's Multiple Comparison Procedure was used to reveal which treatments were significantly different.

\section{Results and discussion}

\section{Dynamics of RONT processes at different initial conditions - effect of seasonality}

The heterotrophic respiration and oxidation processes were studied by measurement of the concentration decrease of the end electron acceptor - oxygen - and depletion of the organic 
Figure 3

Dynamics of oxygen consumption (a) and organic matter oxidation (b) in May and July
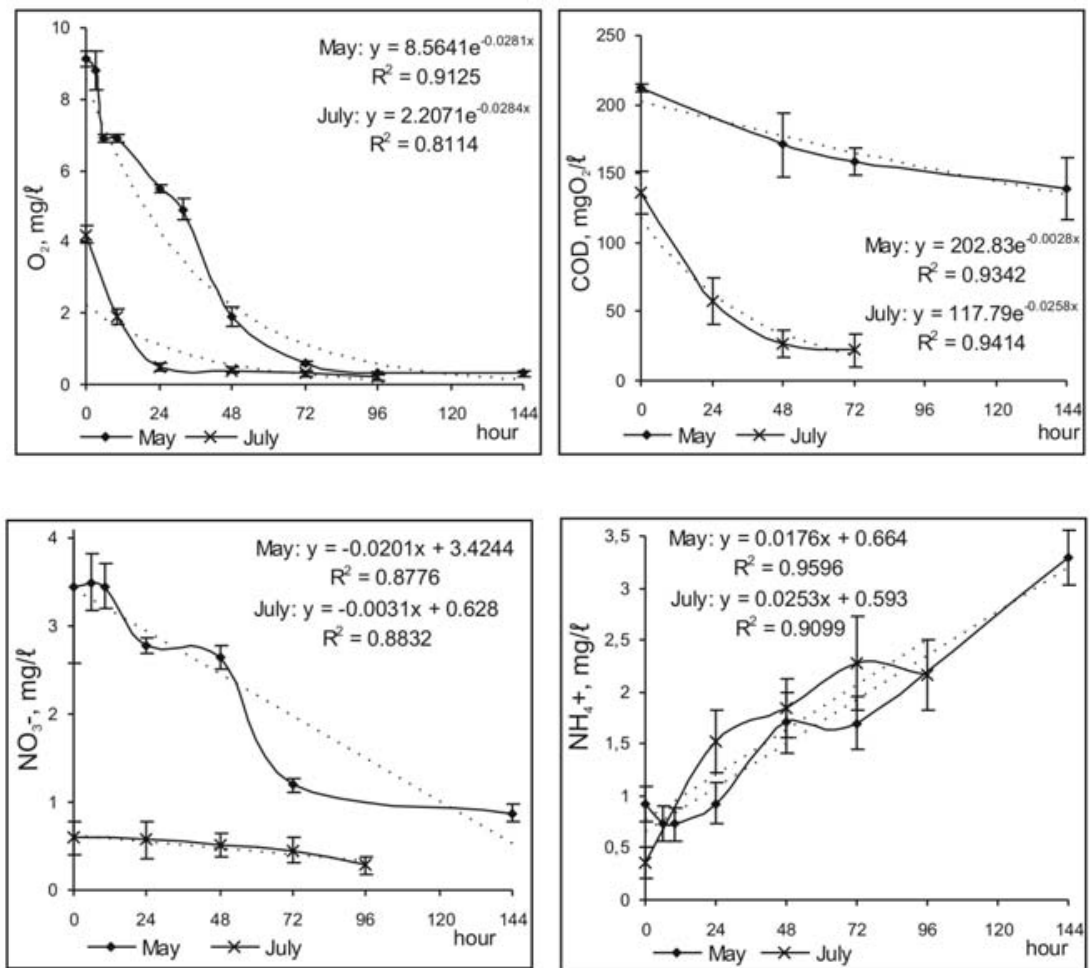

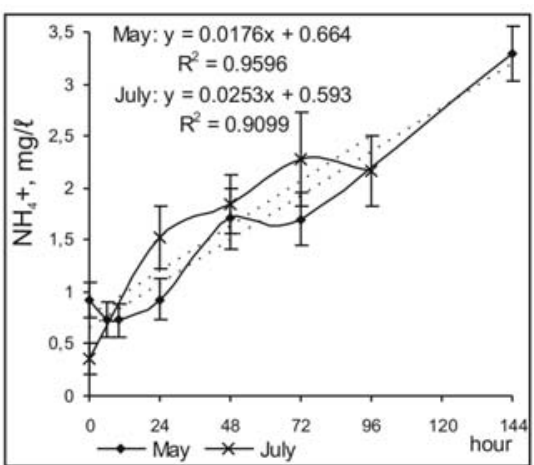

Figure 4

Dynamics of nitrate decrease (a) and ammonium accumulation (b) in May and July content in the closed incubation system of the chambers. Photosynthetic processes were limited by the absence of light and the removal of the upper autotrophic biofilm at sampling. Variations of $\mathrm{pH}$ for the complete period of incubation were in the order of 7.3 to 7.7 in May and 7.8 to 8.0 in July.

During the high-water level in spring, the initial oxygen concentration was $9.12 \mathrm{mg} / \ell$ ( $92.2 \%$ saturation) and the temperature of the hyporheic water was $12.9^{\circ} \mathrm{C}$. The dynamics of oxygen depletion (Fig. 3a) in May presented a typical exponential curve $\left(R^{2}=0.913\right)$ with rapid depletion between 0 and $10 \mathrm{~h}$, followed by a gradual decrease in oxygen concentration up to $10 \%$ at $72 \mathrm{~h}$. For the period 72 to $144 \mathrm{~h}$, the oxygen levels varied weakly around $0.5 \mathrm{mg} / \ell$ and were practically similar. In July, low water levels and high environmental temperature affected the initial oxygen concentrations and the simulation process started from an initial oxygen level of $4.2 \mathrm{mg} / \ell$ and a temperature of $22.6^{\circ} \mathrm{C}$. These conditions led to quick development of the respiration process in closed chambers and the significant depletion of oxygen at $24 \mathrm{~h}$. The dynamics of the process werewas significantly different in comparison with the dynamics during the high-water period $(P<0.05$, Kruskal-Wallis). The results obtained presumed the formation of anaerobic conditions in some sediment microhabitats and achievement of anaerobic degradation of organic matter during the summer low-flow period.

The organic matter content in the chambers, measured as COD, decreased according to exponential dynamics (Fig. $3 \mathrm{~b}$ ), but the complete depletion of organics was not recorded The lower initial COD concentration in July resulted in significantly more effective organic matter oxidation $(P<0.05$, Kruskal-Wallis).

Simulations in the chambers showed certain retention of the denitrification process (Fig. $4 \mathrm{a})$ in the first phases $(0-10$ $\mathrm{h}$ in May; 0 - $24 \mathrm{~h}$ in July). For this period, a decrease in the nitrate concentration in the system was not measured because of the need for some oxygen decrease and initial adaptation of the microbial consortium for commencement of denitrification. The analyses of the effect of different starting conditions presented an interesting trend. High nitrate concentrations were observed in the studied river system during periods of high flow because of intensive farming in this region. During the spring, denitrification occurred simultaneously with aerobic respiration and after $72 \mathrm{~h}$ its dynamics did not develop further. This fact indicated the presence of a buffering capacity for high nitrate concentrations in the sediments and good adaptability of the system for utilisation of all metabolic possibilities, by biofilm structuring and formation of different conditions in microhabitats. At low nitrate levels in July (Fig. 4a), denitrification was the alternative aerobic respiration metabolic pathway. The real process advance was observed after $24 \mathrm{~h}$ at oxygen depletion in the experimental system. The difference between the 2 experimental variants was significant $(P<0.05$, KruskalWallis) and the process dynamics was affected by different initial conditions.

The accumulation of ammonium ions in sediments during the 2 study seasons had similar dynamics (Fig. 4b). Ammonification was not influenced significantly $(P>0.05$, Kruskal-Wallis) by the season but the process curve had a steeper slope in July.

\section{RONT processes in deeper anoxic sediments}

The oxygen concentration was further reduced by half in part of the incubated chambers in July. This manipulation did not significantly change the respiration dynamics $(P>0.05$, Kruskal-Wallis). In both types of chambers the depletion of oxygen was rapid and was registered in the first $24 \mathrm{~h}$ (Fig. 5a). The $1^{\text {st }}$ phase of COD oxidation also passed with a quick reduction of organic content (Fig. 5b). Its development was proportional to oxygen consumption. The COD had similar values at $24 \mathrm{~h}$ in aerobic and anoxic conditions $\left(58 \mathrm{mg} \mathrm{O}_{2} / \ell\right)$. During the next stage, the oxidation process presented different 

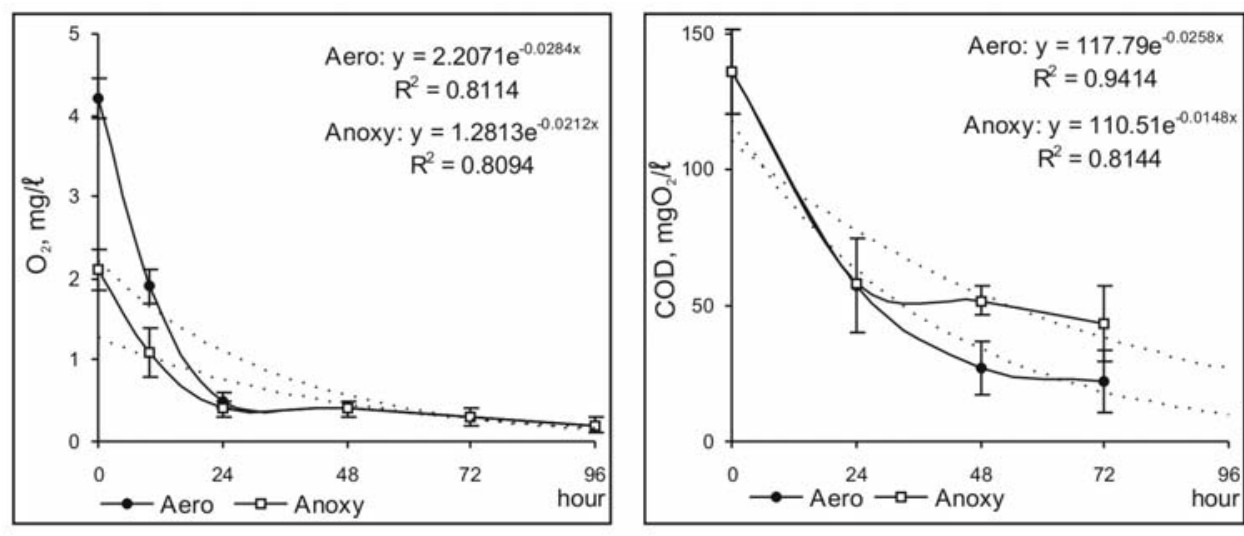

\section{Figure 5}

Dynamics of oxygen consumption (a) and organic oxidation (b) in chambers with natural aerobic (aero) and anaerobic (anoxic) conditions
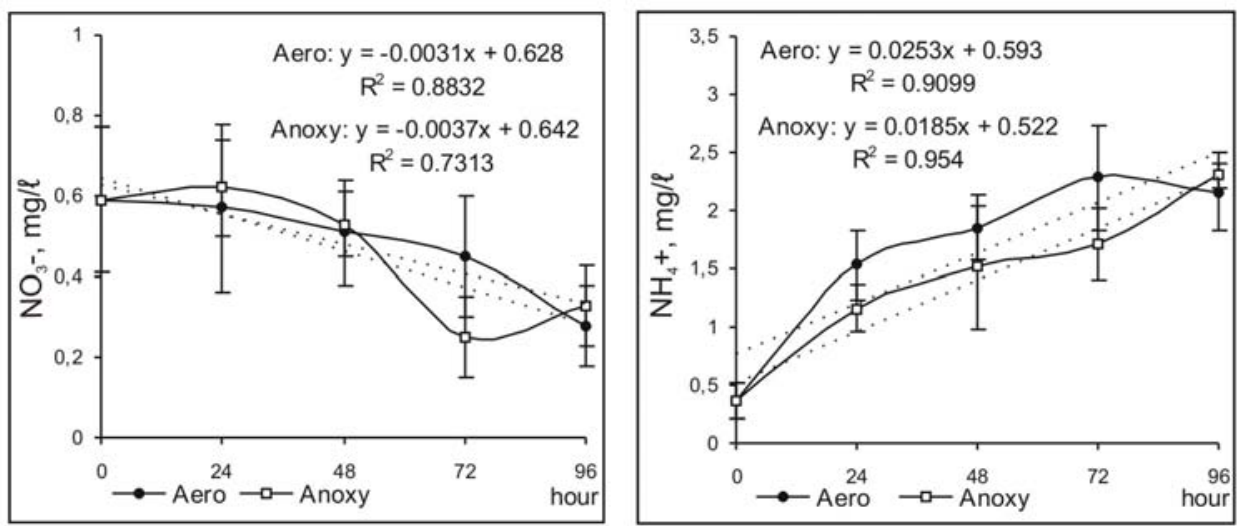

Figure 6

Dynamics of nitrate decrease (a) and ammonium accumulation (b) in chambers with natural aerobic (aero) and anaerobic (anoxic) conditions dynamics: COD continued to fall up to $22.16 \mathrm{mg} \mathrm{O}_{2} / \ell$ at $72 \mathrm{~h}$ in aerobic chambers but the values of this parameter in anoxic chambers stayed in the range 40 to $50 \mathrm{mg} \mathrm{O}_{2} / \ell$ until the end of the experiment.

Denitrification in aerobic conditions was characterised by a gradual decrease in the nitrate concentration over the whole study period. This tendency was also observed in anoxic conditions but for the first $48 \mathrm{~h}$. At $72 \mathrm{~h}$ a sharp reduction of nitrate content and increased denitrification activity of the microbial biofilm were observed (Fig. 6a). The ammonium accumulation had similar dynamics but was faster under aerobic conditions (Fig. 6b).

\section{Respiration rates and nitrogen transformation process rates}

The mean respiration rate measured in the simulation chambers was $0.276 \mathrm{mg} \mathrm{O}_{2} / \ell \cdot h$ in May, and 0.125 and $0.062 \mathrm{mg} \mathrm{O}_{2} / \ell \cdot h$ in July, for aerobic and anoxic bioreactors respectively. The rates of respiration during the different phases of the process are presented in Fig. 7a. The rates at high flow and unaffected low flow conditions were similar $\left(0.45 \mathrm{mg} \mathrm{O}_{2} / \ell \cdot h\right)$ for the first $24 \mathrm{~h}$. In May this value was maintained for the next 24 to $48 \mathrm{~h}$ period. Analysis of oxygen consumption dynamics and respiration rates during the different phases showed an identical rate of oxygen depletion over a wide concentration range of 3 to $10 \mathrm{mg} \mathrm{O}_{2} / \ell$ for this sediment system. At about $2 \mathrm{mg} \mathrm{O}_{2} / \ell$, the rate was decreased by half and below $0.5 \mathrm{mg} \mathrm{O}_{2} / \ell$ it was insignificant $\left(0.01 \mathrm{mg} \mathrm{O}_{2} / \ell \cdot h\right)$.

These results for Iskar River were half the rates that Uehlinger et al., 2002 reported for sand sediments of a warm desert stream with high nutrient concentrations. This result indicated the highly effective functioning of the studied microbial community. Pusch and Schwoerbel (1994) carried out a similar experiment in a mountain stream with very similar characteristics to the Iskar River and studied the respiration rates monthly for 2 years.

The nitrogen transformation processes proceeded at slower rates than the oxygen consumption. In July, denitrification worked as an alternative of aerobic respiration and its rate increased gradually. The mean value was $0.004 \mathrm{mg} \mathrm{NO}_{3} / \ell \cdot h$ for the 2 low flow simulations. The distinction was found in the different phases - under anoxic conditions the rate sharply increased during the 48-72 $\mathrm{h}$ period, followed by process retention and a weak accumulation of nitrates in the last stage (Fig. $7 b)$.

The observed tendency of simultaneous nitrate depletion and oxygen consumption in May was explained by the precise division of the 2 opposite processes over time and the main denitrification rate of $0.027 \mathrm{mg} \mathrm{NO} / \ell \cdot h$ varied in inverse proportion to the respiration rate during each phase, even when the total dynamics of the 2 processes was similar.

The results obtained confirmed a strong positive correlation of denitrification processes in sediments with nitrate concentrations and an ambiguous effect of oxygen and organic matter content on the system (Pinay et al., 2002). Baker and Vervier (2004) also concluded that deep anoxic in situ conditions were not obligatory for the occurrence of denitrification. The authors measured a potential process rate by nitrate depletion in the riparian zone and the mean value $\left(0.07 \mathrm{mg} \mathrm{NO}_{3} / \ell \cdot h\right)$ was greater during the high-flow period.

The dynamics of ammonium accumulation in the system did not show a significant influence of the different incubation conditions. For all the variables of the simulation, the development of the process was linear and the mean ammonification rate was $0.02-0.025 \mathrm{mg} \mathrm{NH}_{4}^{+} / \ell \cdot h$. The differences became 


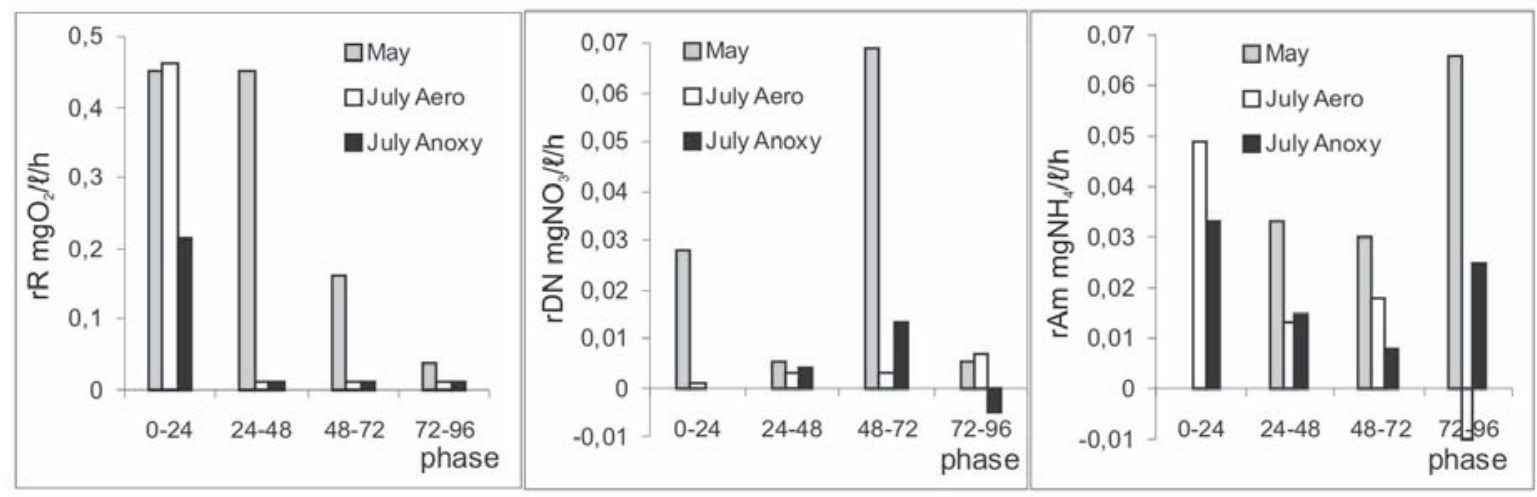

Figure 7

Rates of respiration (a), denitrification (b) and ammonification (c) during the different phases of the processes

evident at stage analysing of the processes (Fig. 7c). In May, the ammonium ions did not change levels in the first $24 \mathrm{~h}$ and the process rate was 0 . Ammonification started after $24 \mathrm{~h}$. The simulation experiments performed in July followed a different trend: the highest rate was measured during the first $24 \mathrm{~h}$. In the later phases this rate decreased and fluctuated about the mean value.

\section{Conclusions}

The performance of RONT-measured analyses and the results obtained showed the dynamics and rate of natural transformation processes in sediments of a river with typical seasonal run-off (the Iskar River). The following key elements were observed:

The depletion of oxygen in a closed simulation system of surface sediment strata was registered between 24 and $72 \mathrm{~h}$, depending on initial concentrations. Fast oxygen reduction and comparatively high process rates were indicators for intensive respiration, facilitated by a heterotrophic microbial consortium and required for good functioning of the ecosystem component studied.

The absence of complete organic matter oxidation in the model system demonstrated the need for a longer experimental period for inclusion of additional anoxic and anaerobic processes for local elimination of higher organic discharges.

The nitrogen transformation processes in the sediments of the upper Iskar River were in mutual dynamic balance and their simultaneous occurrence was due to precise, adaptive spatial and temporal division.

\section{Acknowledgments}

This work was funded by the European Commission, Contract EVK-CT-2002-00112 “"Evaluation and improvement of water quality models for application to temporary waters in Southern European catchments - TempQsim"' and the project "'Ecological modeling of water purification processes in critical control points of upper subcatchment of Iskar River", sponsored by National Scientific Fund to the Ministry of Education and Science. The authors would like to thank Elmira
Daskalova, Lyubomir Kenderov and Dimiter Parvanov for their valuable assistance in field work and laboratory analyses. We thank the two anonymous reviewers for providing useful comments and suggestions.

\section{References}

ALLAN JD (1995) Stream Ecology - Structure and Function of Running Waters. Chapman \& Hall, London. 388 pp.

BAKER MA and VERVIER P (2004) Hydrological variability, organic matter supply and denitrification in the Garonne River ecosystem. Freshwater Biol. 49 181-190.

BOU C (1974) Recherches sur les eaux souterraines: Les méthodes de récolte dans les eaux souterraines interstitielles. Ann. Spéléol. 29 611-619.

BNS-EN-ISO (1989) Bulgarian Standards (4 ${ }^{\text {th }}$ edn.) Standardisation, Sofia, Bulgaria.

DODDS WK and BROCK J (1998) A portable flow chamber for in situ determination of benthic metabolism. Freshwater Biol. 39 49-59.

KUKURIN K, RIBAROVA I, KALINKOV P, NINOV P, TOPALOVA $\mathrm{Y}$ and FROEBRICH J (2004) Winter low flow spatial dynamics for selected reach of Iskar River upstream. Proc. Int. Conf. of Ecology. 7-10 June, Slynchev Brjag, Bulgaria.

KUKURIN K (2005) Perceptual model for the seasonal dynamics of the upper stream runoff of the Iskar River. Proc. of the $1^{\text {st }}$ Int. Conf. BULAQUA. 7-8 June, Sofia, Bulgaria.

NAEGELI MW and UEHLINGER U (1997) Contribution of the hyporheic zone to ecosystem metabolism in a prealpine gravel-bed river. J. N. Am. Benthol. Soc. 16 (4) 794-804.

PINAY G, CLEMENT JC and NAIMAN RJ (2002) Basic principles and ecological consequences of changing water regimes on nitrogen cycling in fluvial systems. Environ. Manage. 30 (4) 481-491.

PUSCH M and SCHWOERBEL J (1994) Community respiration in hyporheic sediments of a mountain stream (Steina, Black Forest). Arch. Hydrobiol. 130 (1) 35-52.

STANDARD METHODS (1989) Standard Methods for the Examination of Water and Wastewater. APHA, AWWA, WPCF, Washington, D.C.

TOPALOVA Y, RIBAROVA I, TODOROVA Y, NINOV P, KUKURIN K, KALINKOV P and TOCKNER K (2006) Evolution of the experimental plan in data collection and verification tactics: Application of HSPF model for Iskar River. Biotechnol. \& Biotechnol. Eq. 20 (3) 83-96.

UEHLINGER U, NAEGELI MW and FISHER SG (2002) A heterotrophic desert stream? The role of sediment stability. W. N. Am. Natur. 62 (4) 466-473. 
Available on website http://www.wrc.org.za ISSN 0378-4738 (Print) = Water SA Vol. 35 No. 5 October 2009 ISSN 1816-7950 (On-line) $=$ Water SA Vol. 35 No. 5 October 2009 